\title{
THE USE OF MILK RECORDS OBTAINED BY DIFFERENT RECORDING SCHEMES IN SIRE EVALUATION OF HOLSTEIN CATTLE IN EGYPT
}

\author{
S. Abou-Bakr, R.R. Sadek, M.K. Hamed, M.A.M. Ibrahim and A.S. Abdel- \\ Aziz
}

Department of Animal Production, Faculty of Agriculture, University of Cairo, Giza, Egypt

\section{SUMMARY}

A total number of 431 complete lactation records of 169 cows representing the first three parities and sired by 50 sires was collected from a private Holstein commercial farm belonging to the International Company for Animal Wealth over three years. Only sires which had at least two daughters having records of at least 70 days lactation period were included. The study aimed at utilizing monthly, bimonthly and trimonthly milk recording schemes in estimating total milk yield (TMY), heritability $\left(h^{2}\right.$ ) and sires' transmitting abilities (STA) for TMY. Data were analyzed according to Harvey (1990). The model underlying each record included sire as a random effect, year and season of calving as fixed effects, and age at calving as a quadratic covariate.

The results showed no significant differences among TMY of the first lactation calculated from monthly, bimonthly and trimonthly milk records. In case of all lactations, the differences (from monthly) were significant when trimonthly recording was used in calculating TMY. The correlation coefficients between TMY of the first lactation estimated from the different schemes ranged from 0.982 to 0.993 . Corresponding crefficients for all lactations ranged from 0.970 to 0.993 .

Estimates of $h^{2}$ of TMY of the first lactation obtained from the different milk records ranged between 0.241 and 0.376 . Highly significant correlation coefficients were found among STA's calculated from the different milk recording schemes. A highly significant rank correlations $(P<0.0001)$ were observed among the rankings of sires according to their transmitting abilities estimated from monthly, bimonthly and trimonthly milk records.

Keywords: Holstein, sire evaluation, milk recording schemes, Egypt

\section{INTRODUCTION}

The monthly test-date procedure for milk recording is widely used in estimating total milk yieid. El-Tawil (1959), Yousef et al. (1961) and Sadek ot al. (1994), reported that once-a-month milk recording system could be applied for estimating TMY in Egyptian buffaloes and Friesian cows with a high degree of accuracy.

Issued by The Egyptian Society of Animal Production 
Applying milk recording schemes with limited number of visits throughout the lactation (bimonthly or trimonthly) may be necessary under Egyptian field conditions, in order to reduced cost, time and effort. The main objective of this work was to utilize monthly, bimonthly and trimonthly milk records in estimating :1)TMY of the first and all lactations of Holstein cows, 2) $h^{2}$ of TMY for the first lactation and 3) STA's of Holstein sires for TMY of the first lactation.

\section{NATERIALS AND METHODS}

The data used in this study were collected from a private Holstein farm located in Giza governorate and belonged to the International Company for Animal Wealth. Data comprised 431 complete lactation records of TMY of 169 Holstein cows sired by 50 sires. Each sire had at least two daugters having records of at least 70 days lactation period. The data covered the first three parities during the period from 1991 to 1993. All cows in this herd are imported from USA since 1991 and were registered in the Holstein Breed Association.

Total milk yield for each cow was calculated by three milk recording schemes:1) Monthly (MON) milk production of each test day was multiplied by 30.5 to calculate the monthly production. Summing up of the monthly production estimates resulted in the TMY, 2) Tests were taken every other month starting either with the first or the second month to produce two sets of records. Milk production of the test day for either bimonthly odd months (BOM) or bimonthly even months (BEM) of the lactation period was multiplied by 61 to calculate the milk production of the two-month intervals between tests. The TMY was then estimated by summing up the production of each two months throughout the lactation period and 3) Tests were taken every three months. Also, two sets of records were produced, trimonthly 1 (TR1), where milk recording started in the first month of lactation and at three-month intervals and trimonthly 2 (TR2), where milk recording started in the second month of lactation and at three-month intervals. Milk production of the test day was multiplied by 91.5 to estimate the production of every three months. The total milk yield was estimated by summing up the production of each three-months throughout the lactation period.

The criteria used for comparing both bimonthly or trimonthly milk records with monthly milk records were: 1) Percentage from monthly $=[a / b * 100]$, 2) Bias from monthly $=a-b$ and 3) Percentage bias from monthly $=(a-b) / b * 100$, where, $a=$ Bimonthly or trimonthly milk records and $b=$ Monthly milk records.

Data were analyzed according to Harvey (1990). The model underlying each record included sire as a random effect, year and season of calving as fixed effects, and age at calving as a quadratic covariate. Simple correlation coefficients between monthly (as standard method) and both bimonthly and trimonthly milk yield records were calculated using SAS program ( SAS Procedure Guide, 1988).

Estimates of heritability for TMY of the first lactation were calculated as: $h^{2}=4 \delta^{2} s /$ $\left(\delta^{2} s+\delta^{2} e\right)$, where, $\delta^{2} s=$ the sire component of variance and $\delta^{2} e=$ the error component of variance. Standard errors for the estimates of $h^{2}$ were computed according to Swiger et al. (1964).

The transmitting abilities of sires was calculated by the Best Linear Unbiased Predictor (BLUP) method (Harvey, 1990). The product-moment correlation was 
calculated using SAS program (SAS, 1988) to measure the correlation among estimates of STA. Spearman's rank correlation was calculated to establish the relationships among the ranking (SAS, 1988) obtained by estimated STA.

\section{RESULTS AND DISCUSSION}

A. Estimation of total milk yield using monthly, bimonthly and trimonthly milk records

The results obtained by El-Tawil (1959), Youssef et al. (1961) and Sadek et al. (1994), recommended that once-a-month milk recording could be applied for estimating total milk yield of Egyptian buffaloes and Friesian with a high degree of accuracy. In the present study total milk yield estimated from monthly recording was considered as the standard method for estimating TMY. All estimates of TMY obtained using different recording schemes will be compared with corresponding monthly estimates.

Table 1 presents the least-squares means (LSM) and standard errors of TMY of the first lactation calculated from monthly, bimonthly and trimonthly milk records of Holstein cows. The results showed that BOM, BEM, TR1 and TR2 milk records $(8010,8063,8078$ and $8184 \mathrm{Kg}$, respectively) overestimated as compared with 7850 $\mathrm{Kg}$ calculated from MON records. All differences, however, were not significant. These findings are supported by the results shown in table (2) which presents the criteria used for comparing bimonthly and trimonthly milk records with monthly records. The different recording schemes could be ranked, according to percent bias from monthly, as BOM, BEM, TR1 and TR2, respectively. This means that as the interval between successive recordings increases the \% bias also increases. The correlation coefficients (Table 3 ) between TMY calculated from monthly records and that estimated from bimonthly and trimonthly milk records were hilghly significant $(P<0.01)$. The values ranged from 0.982 between TR2 with MON to 0.993 for either BOM or BEM with MON.

Table 1. Least-Squares means (LSM) and standard errors (SE) of total milk yield of the first lactation calculated from monthly, bimonthly and trimonthly milk records $(\mathrm{N}=211)$

\begin{tabular}{lcc}
\hline & LSM & SE \\
\hline $\begin{array}{l}\text { Monthly records } \\
\text { Bimonthly records }\end{array}$ & 7850 & 362.1 \\
Bimonthly odd months & 8010 & 360.5 \\
Bimonthly even months & 8063 & 382.6 \\
Trimonthly records & & \\
Trimonthly-1 & 8078 & 370.9 \\
Trimonthly-2 & 8184 & 382.2 \\
\hline
\end{tabular}

In the case of all lactations (Table 4), the differences between estimates of TMY calculated from bimonthly (odd or even months) and that of MON records were not significant. While, the differences were highly significant $(P<0.0120$ and $P<0.0002)$ when TR1 and TR2 records were used for estimateing TMY. Table 5 presents that 
the highest bias $(564 \mathrm{Kg}$ ) was obtained when using TR2 records for estimating TMY, while the lowest was observed in case of . The correlation coefficients (Table 6) between TMY of all lactations calculated from monthly records and that estimated from bimonthly and trimonthly records were highly significant $(P<0.01)$. The values ranged from 0.970 between TR1 with MON to 0.991 for BEM and MON.

Table 2. A comparison of bimonthly and trimonthly milk records with monthly milk records for estimating total milk yield of the first lactation $(N=211)$

\begin{tabular}{llll}
\hline & $\begin{array}{c}\% \text { of } \\
\text { monthly }\end{array}$ & $\begin{array}{l}\text { bias } \\
(\mathrm{Kg})\end{array}$ & $\begin{array}{l}\text { Percent } \\
\text { bias }\end{array}$ \\
\hline Bimonthly records & & & \\
Bimonthly odd months & $102 \pm 0.26$ & $200 \pm 21.4$ & $2.4 \pm 0.26$ \\
Bimonthly even months & $103 \pm 0.28$ & $205 \pm 21.7$ & $2.5 \pm 0.28$ \\
$\begin{array}{l}\text { Trimonthly records } \\
\text { Trimonthly-1 }\end{array}$ & $104 \pm 0.40$ & $336 \pm 34.1$ & $4.0 \pm 0.40$ \\
Trimonthly-2 & $104 \pm 0.46$ & $360 \pm 34.5$ & $4.4 \pm 0.46$ \\
\hline
\end{tabular}

The comparisons between the four recording schemes examined (BOM, BEM, TR1 and TR2) indicated that bias and percent bias increase as the interval of recording increases. These results are in accordance with those obtained by El-Tawil (1959), Youssef et al. (1961) on Egyptian buffaloes and Friesian cattle and Bayley et al. (1952) on Holstein cows. Bimonthly scheme appeared to be satisfactory and economically feasible for practical application, since the correlation coefficients between TMY estimated by bimonthly and monthly milk records are very high. Using bimonthly scheme as an accurate procedure for estimating total milk yield was supported by Van Vleck and Henderson (1961); Keown and Van Vleck (1971): Pardhan (1988) and Hamed (1995).

Table 3. The correlation coefficients between total milk yield of the first lactation calculated from monthly, bimonthly and trimonthly milk records

\begin{tabular}{lcccc}
\hline & BOM & BEM & TR1 & TR2 \\
\hline MON & $0.993^{* *}$ & $0.993^{\text {*n }}$ & $0.983^{* *}$ & $0.982^{\text {** }}$ \\
\hline$*=\mathrm{P}<0.01$ & & & &
\end{tabular}

Table 4. Least-Squares means (LSM) and standard errors (SE) of total milk yieldc of all lactations calculated from monthly, bimonthly and trimonthly milk records $(N=431)$

\begin{tabular}{lll}
\multicolumn{1}{c}{ records $(\mathrm{N}=431)$} & SSM \\
\hline & 7855 & 318.2 \\
\hline Monthly records & & \\
Bimonthly records & 8130 & 315.4 \\
Bimonthly odd months & 8107 & 332.9 \\
Bimonthly even months & & \\
Trimonthly records & 8258 & 320.9 \\
Trimonthly-1 & 8324 & 343.8 \\
Trimonthly-2 & & \\
\hline
\end{tabular}


Table 5. A comparison of bimonthly and trimonthly milk records with monthly milk records for estimating total milk yield of all lactations $(N=431)$.

\begin{tabular}{lccc}
\hline & \%of monthly & bias $(\mathrm{Kg})$ & Percent bias \\
\hline Bimonthly records & & & \\
Bimonthly odd months & $103 \pm 0.28$ & $237 \pm 17.7$ & $3.4 \pm 0.28$ \\
Bimonthly even months & $104 \pm 0.22$ & $282 \pm 15.6$ & $3.7 \pm 0.22$ \\
Trimonthly records & & & \\
Trimonthly-1 & $105 \pm 0.46$ & $372 \pm 28.7$ & $5.4 \pm 0.41$ \\
Trimonthly-2 & $107 \pm 0.39$ & $564 \pm 28.2$ & $7.4 \pm 0.39$ \\
\hline
\end{tabular}

B. Estimation of heritability of total milk yield of the first lactation.

Estimates of sire and error components of variance and heritability and their standard errors for TMY of the first lactation calculated from monthly, bimonthly and trimonthly milk records are presented in table 7. Compared to monthly milk records, the percentages of variance attributed to sire in each of BEM and TR2 were higher $\left(9.4\right.$ and 8.4 , respectively) than that of MON (7.9). The estimates of $h^{2}$ of TMY of the first lactation calculated from BEM and TR2 were also higher $(0.376$ and 0.336 , respectively) than the corresponing estimate of $h^{2}$ obtained from MON $(0.314)$. The values of percentage of sire variance in case of BOM and TR1 were almost similar (6.0 and 6.1, respectively) and less than that of monthly records. the estimates of $h^{2}$ for BOM and TR1 were almost equal $(0.241$ and 0.243 , respectively) and less than the estimate of $h^{2}$ of TMY calculated from MON (0.314).

Table 6. The correlation coefficients between total milk yield of all lactations calculated from monthly, bimonthly and trimonthly milk records

\begin{tabular}{ccccc}
\hline & BOM & BEM & TR1 & TR2 \\
\hline MON & $0.988^{* \prime \prime}$ & $0.991^{\prime \prime}$ & $0.970^{\prime \prime \prime}$ & 0.975 \\
\hline
\end{tabular}

$* *=0.01$

Table 7. Estimates of sire $\left(\delta^{2} s\right)$, and error $\left(\delta^{2}\right)$ component, of variance and heritability $\left(h^{2}\right)$ and their standard errors (SE) for total milk yield of the first lactation

\begin{tabular}{lcccccc}
\hline & $\delta^{2}{ }_{s}$ & $V \%^{*}$ & $\delta^{2}$ & $h^{2}$ & $S E$ \\
\hline $\begin{array}{l}\text { Monthly records } \\
\text { Bimonthly records }\end{array}$ & 463817 & 7.9 & 5438643 & 0.314 & 0.257 \\
$\begin{array}{l}\text { Bimonthly odd months } \\
\text { Bimonthly even months }\end{array}$ & 376884 & 686423 & 9.4 & 5891446 & 0.241 & 0.250 \\
$\begin{array}{l}\text { Trimonthly records } \\
\text { Trimonthly-1 }\end{array}$ & 402209 & 6.1 & 6214795 & 0.243 & 0.251 \\
$\quad$ Trimonthly-2 & 541803 & 8.4 & 5909768 & 0.336 & 0.259 \\
\hline
\end{tabular}

- The sire variance component as percentage of the total variance. 


\section{Estimation of sires' transmitting abilities}

The minimum and maximum values of sires' transmitting abilities for 50 Holstein bulls are presented in Table (8). The distribution of sires' transmitting abilities (Table 9) showed that about $48 \%$ of the bulls have negative transmitting abilities in case of MON and BEM records. In the meantime, the percentage reached 52,46 and $50 \%$ in case of BOM, TR1 and TR2, respectively. Compared with monthly milk records, the percentages of bulls having the same rank are $28,44,28$ and $26 \%$, for BOM. BEM, TR1 and TR2, respectively. When the top five sires (the top $10 \%$ ) were identified according to their transmitting abilities obtained from monthly, bimonthly and trimonthly milk records, the same $4,4,4$ and 5 sires were chosen for BOM, BEM, TR1 and TR2, respectively Table (10).

Table 8. Minimum and maximum values of sires' transmitting abilities for total milk yield of the first lactation

\begin{tabular}{lcc}
\hline & Minimum & Maximum \\
\hline Monthly records & -712 & 769 \\
Bimonthly records & -629 & 650 \\
Bimonthly odd months & -835 & 937 \\
Bimonthly even months & & \\
Trimonthly records & -725 & 717 \\
Trimonthly-1 & -798 & 820 \\
Trimonthly-2 & & \\
\hline No. of sires $=50$ & &
\end{tabular}

Table 9. Distribution of sires' transmitting abilities (STA) for total milk yield of the first lactation

\begin{tabular}{lcccc}
\hline & \multicolumn{4}{c}{ STA estimates } \\
\cline { 2 - 5 } & \multicolumn{2}{c}{ Positive } & \multicolumn{2}{c}{ Negative } \\
\cline { 2 - 5 } & No. of sires & $\%$ & No. of sires & $\%$ \\
\hline Monthly records & 26 & 52 & 24 & 48 \\
Bimonthly records & 24 & 48 & 26 & 52 \\
Bimonthly odd months & 26 & 52 & 24 & 48 \\
Bimonthly even months & 27 & 54 & 23 & 46 \\
Trimonthly records & 25 & 50 & 25 & 50 \\
\hline Trimonthly-1 & & & & \\
Trimonthly-2 & & & & \\
\hline
\end{tabular}

Table 10. Ranking of the top five bulls (the top 10\%) according to their transmitting abilities for total milk yield of the first lactation

\begin{tabular}{ccccc}
\hline MON & BOM & BEM & TR1 & TR2 \\
\hline 1 & 1 & 1 & 1 & 1 \\
2 & 2 & 2 & 2 & 2 \\
3 & 3 & 3 & 3 & 3 \\
4 & 4 & 6 & 5 & 5 \\
5 & 6 & 5 & 13 & 4 \\
\hline
\end{tabular}


The product-moment correlation coefficients (Table 11) between estimates of sires' transmitting abilities obtained from monthly, bimonthly and trimonthly milk records were larger in all cases than 0.97. These figuers demonstrated how close were the estimates of sires' transmitting abilities calculated from different recording schemes. In the meantime,the rank correlation coefficients among the rankings of sires according to their transmitting abilities were highly significant $(p<0.0001)$. The values of Spearman rank correlations ranged from 0.982 (between TR1 and MON) to 0.993 (between BEM and MON).

Table 11. Product-moment and Spearman rank correlations between values of sires' transmitting abilities for total milk yield of the first lactation

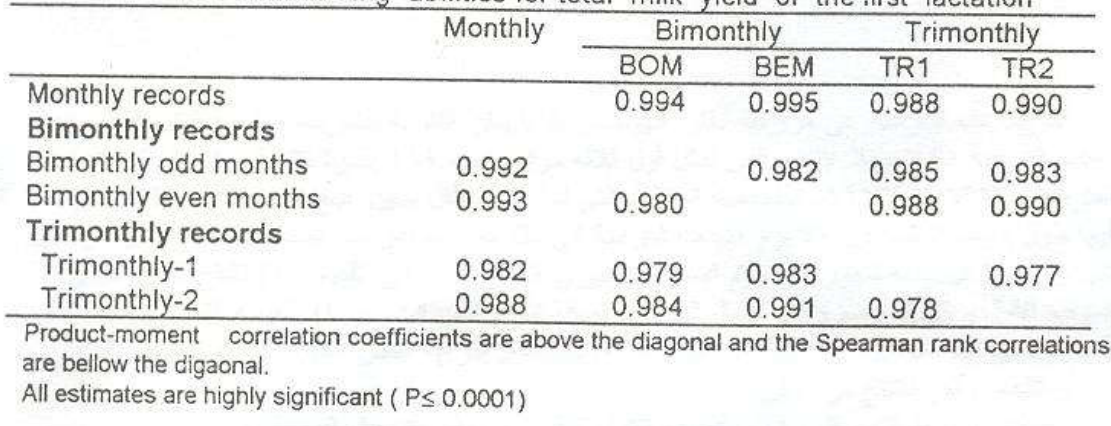

The above mentioned results indicate that bimonthly and trimonthly milk recording schemes, as compared with monthly test-data records, could be utilized in estimating total milk yield, heritability and sires' transmitting abilities for Holstein cattle with reasonable accuracy.

\section{REFERENCES}

Bayley, N.D., R.M. Liss and J.E. Stallard, 1952.Comparison of bimonthly and quarterly testing with monthly testing for estimating dairy cattle production.J.Dairy Sci., 35:350-355

El-Tawil, E.A., 1959. The accuracy of some different milk recording systems and their importance in evaluating dairy cattle and buffaloes. M.Sc. Thesis, Fac. Of Agric., Cairo Univ., Egypt.

Hamed, M.K., 1995. Accurcy of bimonthly and trimonthly milk recording systems for dairy cattle in Egypt. Annals of Agric. Sci., Moshtohor, 33: 659-669.

Harvey, W.R., 1990. User's Guide for LSMLMW. Mixed model least-squares and maximum likelihood computer program. PC-Version 2, Ohio State Univ., Columbus, USA, (Mimeograph).

Keown , J.F. and L.D. Van Vleck, 1971. Selection on test-day fat percentage and milk production.J. Dairy Sci., 54:199-203

Pradhan, S., 1985. A short note on the estimation of the milk yield of a cow. Nepalese J. Anim.Sci., 13-18 (Anim.Breed.Abstr., 1988, 56:620) 
Sadek,R.R, K.M. Mourad, M.A.M. Ibrahim, S.Abou-Bakr and A.S Abdel-Aziz, 1994. Genetic parameters of milk yield of Egyptian buffaloes calculated from daily and monthly test-date records. Buffalo. J. 3: 197-200

SAS, 1988. Statistical Analysis System. SAS Usier's Guide: Statistics. SAS Institute Inc. Editors, Cary, NC.

Swiger, L.A., W.R. Harvey, D.O. Everson and K.E. Gregory, 1964. The variance of intraclass correlation involving groups with one observation. Biometrics, 20: 818.

Van Vleck, L.D. and C.R. Henderson, 1961. Regression factors for extending part lactation milk records. J.Dairy Sci., 44: 1085-1092.

Youssef, A.A., Y.M. Tolba and S.D. Ahmed, 1961. Estimation of buffalo milk yield by recording at different intervales. J. Anim. Prod. U.A.R.: 75-81 
إستخدام سجلات اللبن المحسوبة بنظم تسجيل مختلفة فى تقييم طلاتق الهولستين في

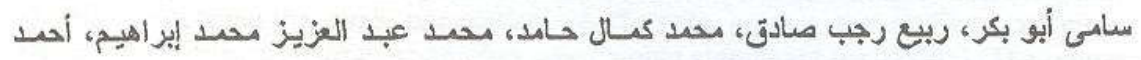

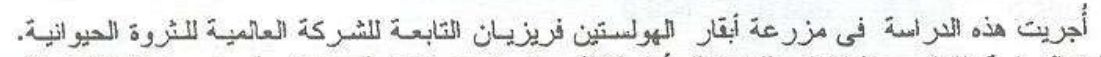

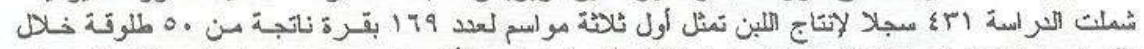

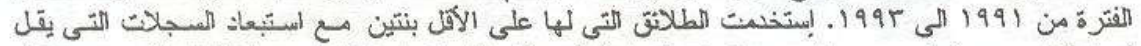

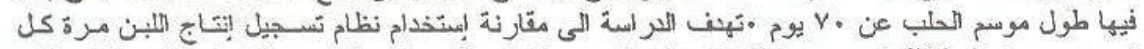

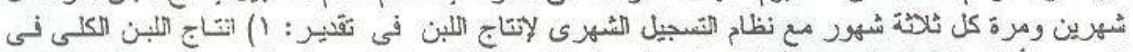

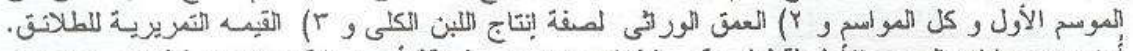

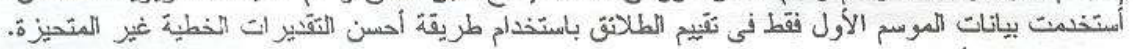

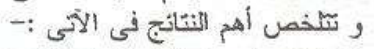

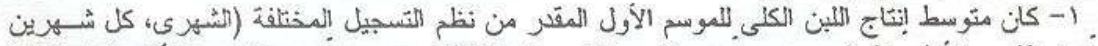

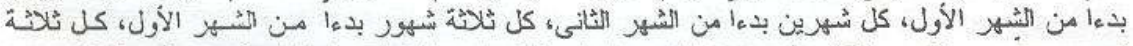

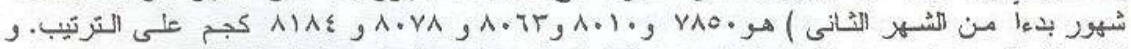

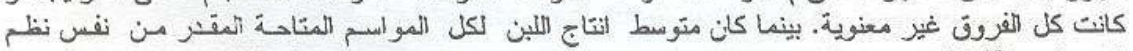

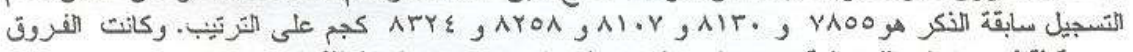

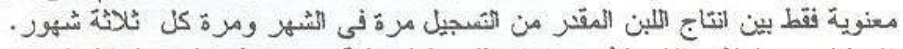

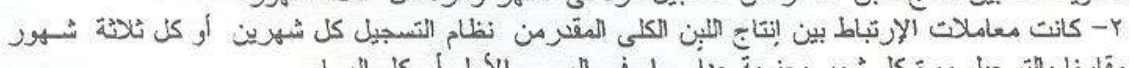

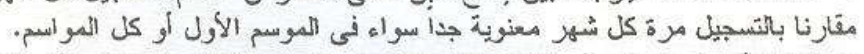

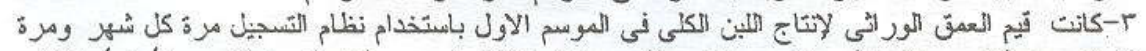

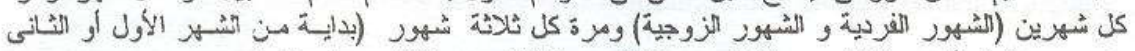

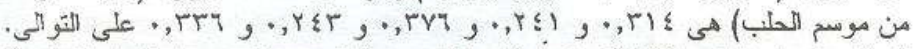

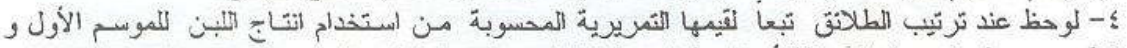

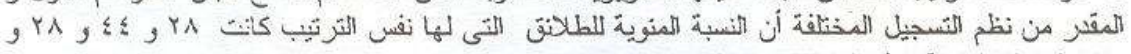

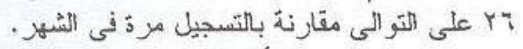

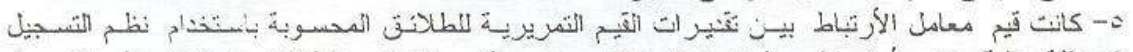

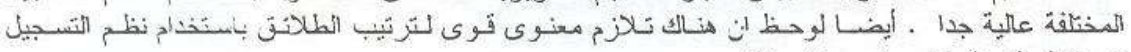

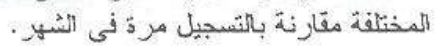

